\title{
The Endocrine Society 2013 Laureate Awards
}

Published online: 14 August 2013

(C) Springer Science+Business Media New York 2013

\section{Citations for the 2013 Fred Conrad Koch Award of The Endocrine Society to Dr Michael O. Thorner}

Michael O. Thorner graduated in medicine with honors in Therapeutics and Applied Pharmacology from the Middlesex Hospital School of Medicine, University of London in 1970. There he came under the spell of Sir John Nabarro, the senior endocrinologist. $\mathrm{He}$ completed fellowship training in Endocrinology and Metabolism at St Bartholomew's Hospital under the mentorship of G. Michael Besser, Phil Lowry, John Landon, Tim Chard, and Lesley Rees. He was at Barts from

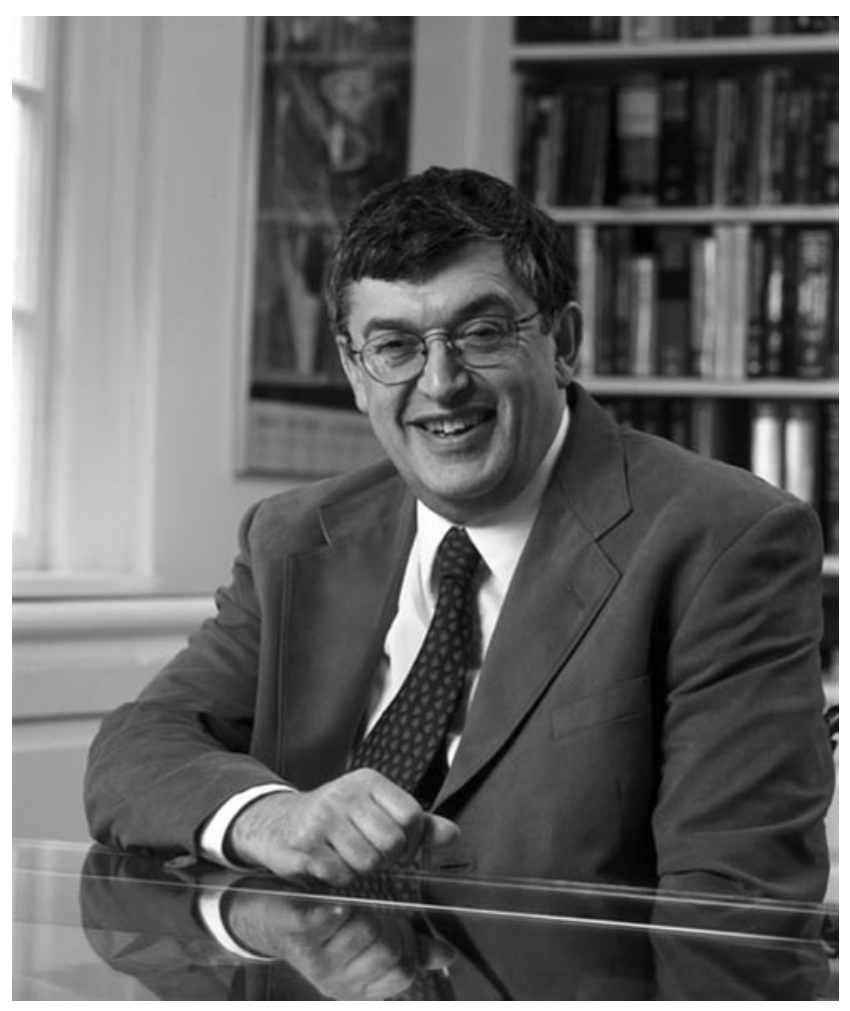

1972 to 1977 , the time of the discovery, sequencing, and synthesis of the hypothalamic hormones, and introduction of immunoassays. The Barts group together with Dr Reginald Hall's group in Newcastle-upon-Tyne, were collaborators with Dr Andrew Schally, who provided the new synthetic hypothalamic hormones for the initial studies in humans. Michael $\mathrm{O}$. Thorner's project was prolactin, which was specifically identified as biochemically separate from growth hormone in the human at about that time, through the work of Henry Friesen and Andrew Frantz. The Barts group was working with a specific inhibitor of prolactin secretion developed by Edward Flueckiger at Sandoz (now Novartis) in Basel. At that time it was not known how bromocriptine inhibits prolactin secretion (before the identification of dopamine receptors). At the University of Virginia, Dr Robert MacLeod's pioneering observations that dopamine is the hypothalamic factor inhibiting prolactin release led to Thorner visiting the University of Virginia. Soon after, Thorner was recruited to the University of Virginia (in 1977) by Drs Edward W. Hook, Robert M. Carey, Robert M. MacLeod, and Julian I. Kitay.

At Virginia, Thorner developed as one of the world's foremost clinical neuroendocrinologists and a renowned basic and clinical investigator of neurohormonal mechanisms of disease. Thorner's work has exemplified the finest combination of clinical and basic research that can be found in any medical field.

Thorner pioneered the use of dopamine agonist drugs in patients with prolactin-secreting pituitary tumors to restore normal prolactin levels, normal gonadal function, cessation of galactorrhea, and reduction of the size of the tumor, obviating the need for pituitary surgery. As a result of Thorner's work, medical treatment, instead of surgery, is now the standard of care for prolactin-secreting tumors.

An astute clinical observation led to the discovery of growth hormone-releasing hormone (GHRH). A patient with acromegaly unexpectedly had hyperplasia rather than an adenoma of the somatotrophs of the pituitary. Thorner identified a 
tumor in the tail of the pancreas; removal of this tumor led to cessation of the excessive growth hormone $(\mathrm{GH})$ secretion within 1 hour. The tumor contained GHRH, and he provided the tumor to Drs Wylie Vale and Roger Guillemin to study. The GHRH was isolated, sequenced and ultimately cloned from the tumor.

Thorner rapidly cloned the GHRH receptor. In Thorner's clinical studies, synthetic GHRH was first administered to normal volunteers and subsequently to children and adults with GH deficiency. Thorner demonstrated that GHRH selectively stimulates GH secretion and that idiopathic GH deficiency is most commonly due to GHRH deficiency. Chronic administration of GHRH restored normal growth in children with GH deficiency.

Together with Dr Cyril Bowers, Thorner demonstrated that the GH-releasing peptide, a synthetic hexapeptide, which acts through a novel and distinct receptor, acts synergistically with GHRH. Thorner's 24-hour infusion studies in normal subjects demonstrated that this compound could stimulate pulsatile GH secretion, and this was the basis for Merck Research Laboratories' choice of a long-acting spiropiperidine analog for human studies. Thorner then led a team who demonstrated that GH secretion in the elderly can be stimulated in a physiologic, pulsatile fashion with a single daily oral dose of this GH secretagogue (MK-677). This finding opened the door to restoration of GH secretion at a level similar to that seen in young adults.

A two-year, double-blind, placebo-controlled study of 65 healthy older men and women was completed. Daily administration of MK-677 significantly increased GH and insulinlike growth factor 1 (IGF-1) levels to those of healthy young adults without serious adverse effects. Mean fat-free mass decreased in the placebo group but increased in the MK-677 group, as did body cell mass. No significant differences were observed in abdominal visceral fat or total fat mass; however, the average increase in limb fat was greater in the MK-677 group than the placebo group. Increased fat-free mass did not result in changes in strength or function.

Based on the results of the above-mentioned study, Thorner has successfully obtained a use patent for growth hormone secretatogues in the treatment of sarcopenia in the elderly, which he is now developing into a venture company. Thus, Thorner is striving to translate his life's work into a therapy to enable the elderly to remain independent for as long as possible.

Thorner's laboratory has developed specific two-site assays for measurement of the two forms of ghrelin, the natural ligand for the GH secretagogue receptor and a ligand for an as-yet unknown receptor. Using these assays, Thorner has demonstrated that long-term starvation ( $>37.5$ hours) leads to suppression of acyl ghrelin (the biologically active form) and enhancement of desacyl ghrelin.

The work could only have succeeded with the close collaborations that Thorner fostered with investigators around the world and from the dedicated work of many close colleagues and staff at the University of Virginia, as well as 33 postdoctoral fellows from the United States, Australia, Brazil, China, Europe, Japan, and the UK. Almost all of them remain in academic medicine and many are leading their own departments and laboratories or programs at their university, the NIH or industry.

Thorner developed the Pituitary Program at the University of Virginia, which is widely recognized as a leading center for the treatment of patients with pituitary and hypothalamic disease. He successfully chaired the Department of Medicine at University of Virginia for nine years and currently holds an endowed professorship in endocrinology. He has received continuous funding from the NIH and the pharmaceutical industry throughout his career. He has served on NIH study sections and as an officer in several professional and scientific societies, including The Endocrine Society. He has received numerous national and international awards for his contributions to the understanding of pituitary disease. He is an elected member of the American Society for Clinical Investigation, the Association of American Physicians, and the American Clinical and Climatological Association and was elected Fellow of the American Academy of Arts and Sciences in 2000.

In summary, Dr Michael O. Thorner is an extraordinary basic and clinical research scientist in the field of endocrinology with landmark contributions to the treatment of pituitary tumors, the discovery of GHRH and its receptor, and the actions and potential uses of GHRH and ghrelin mimetics in the treatment of sarcopenia of aging. His work has elevated the entire field of endocrinology in its ability to make a real difference in the lives of patients.

Robert Carey

\section{Citation for the 2013 Ernst Oppenheimer Award of The Endocrine Society to Dr Doris A. Stoffers}

Doris A. Stoffers, MD, PhD, Professor of Medicine at the Perelman School of Medicine at the University of Pennsylvania, is the recipient of The Endocrine Society's 2013 Ernst Oppenheimer Award. Dr Stoffers has made a series of seminal observations that have informed our understanding of pancreas development and are improving our understanding of diabetes and its treatment.

Dr Stoffers attended Stuyvesant High School in New York City and completed her undergraduate studies in chemistry at The Johns Hopkins University. She then obtained MD and $\mathrm{PhD}$ degrees from Johns Hopkins. Her $\mathrm{PhD}$ in neuroscience was completed under the mentorship of Elizabeth Eipper and Richard Mains, previous recipients of this Award, and focused on the molecular regulation of peptide amidation by peptidylglycine alpha amidating monooxygenase (PAM). She completed postgraduate medical training at Harvard Medical School (Internal Medicine residency at the Brigham and Women's Hospital and Endocrinology fellowship at 


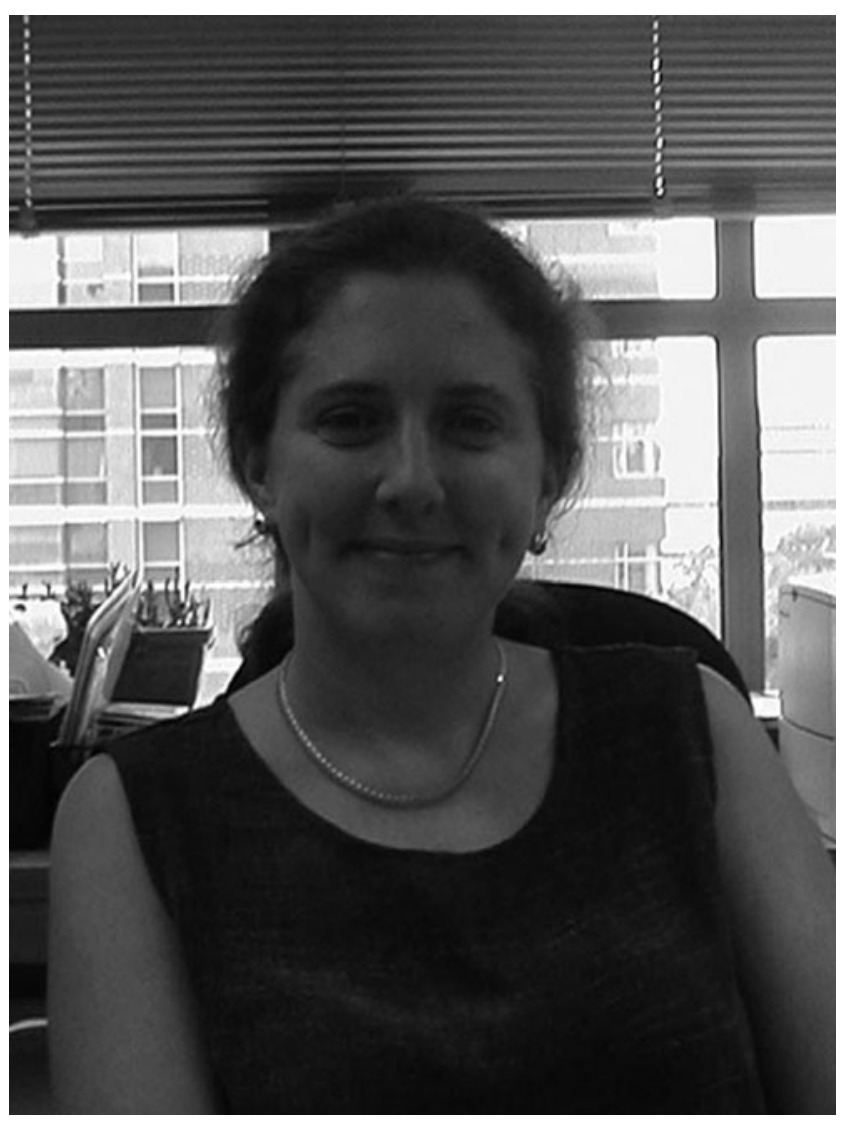

Massachusetts General Hospital). Her fellowship included formative postdoctoral training in the Laboratory of Molecular Endocrinology directed by Joel Habener, an internationally recognized scientist with an outstanding record of novel scientific discovery and of mentoring physician scientists. Here she developed her interest in pancreatic $\beta$-cells, which continues to this day. At that time the central role of the $\beta$-cell in the pathophysiology of type 2 diabetes was not yet widely appreciated.

During this time Dr Stoffers discovered that a mutation in the pancreatic homeodomain transcription factor Pdx1 was responsible for a form of early-onset diabetes, MODY-4 (maturityonset diabetes of young). This occurred simultaneously with the discovery of several other transcription factors as loci responsible for MODY-1, $-3,-5$, and -6 by other investigators. Thus, many forms of monogenic diabetes became recognized as disorders of transcriptional regulation of pancreatic $\beta$-cell development and function. During this fast-moving period in $\beta$-cell biology and genetics when the transcriptional hierarchy of $\beta$ cell development was gradually being elucidated, Dr Stoffers began to investigate the molecular mechanisms surrounding Pdx1 action in an effort to illuminate the molecular "details" that could lead to the identification of novel therapeutic targets and strategies for the treatment of diabetes. The foundation of her work is that the genetic or pharmacologic manipulation of such targets would promote $\beta$-cell regeneration in vivo or ex vivo to increase the supply and function of the severely limited number of human islets available for transplantation.

As part of these efforts, Dr Stoffers identified a novel Pdx1 protein partner, Pcifl, that interacts with the $\mathrm{C}$ terminus of Pdx 1 to negatively regulate its function. Pcifl functions as a substrate adaptor to recruit Pdx1 into a Cul3-E3 ubiquitin ligase complex, with resultant targeting of Pdx1 for proteasomal degradation. A genetic mouse model of Pcifl disruption established the role of Pcifl in vivo to regulate Pdx1 protein stability and thereby influence the phenotype of Pdx1 deficiency. Dr Stoffers uncovered the critical role of Pdx1 in islet compensation for dietinduced insulin resistance and identified endoplasmic reticulum (ER) homeostasis as a target for Pdx1 action through direct regulation of ER genes, including Atf4, Wfsl, and Erollb. She also discovered the specific role of Pdx1 in endocrine pancreas progenitors, with potential applications to embryonic stem cell and inducible pluripotent stem cell differentiation.

Dr Stoffers is strongly motivated by discovery and by mentorship of trainees working in her laboratory. She has also played important and broader roles in the scientific community, including Associate Editorship of The Journal of Clinical Investigation, membership on the Cellular Aspects of Diabetes and Obesity (CADO) NIH study section, and leadership roles within the Penn Diabetes Research Center. She was elected to the American Society of Clinical Investigation in 2007 and to Association of American Physicians in 2012.

For her influential discoveries at the interface of human diabetes genetics and the transcriptional regulation of pancreas development and function, Dr Stoffers is most deserving of this year's Oppenheimer Award.

Alvin Powers

\section{Citation for the 2013 Robert H. Williams Distinguished Leadership Award of The Endocrine Society to Dr John W. Funder}

The 2013 Robert H. Williams Distinguished Leadership Award is presented to John W. Funder of Prince Henry's Institute in Melbourne, Australia. John was born in Adelaide,

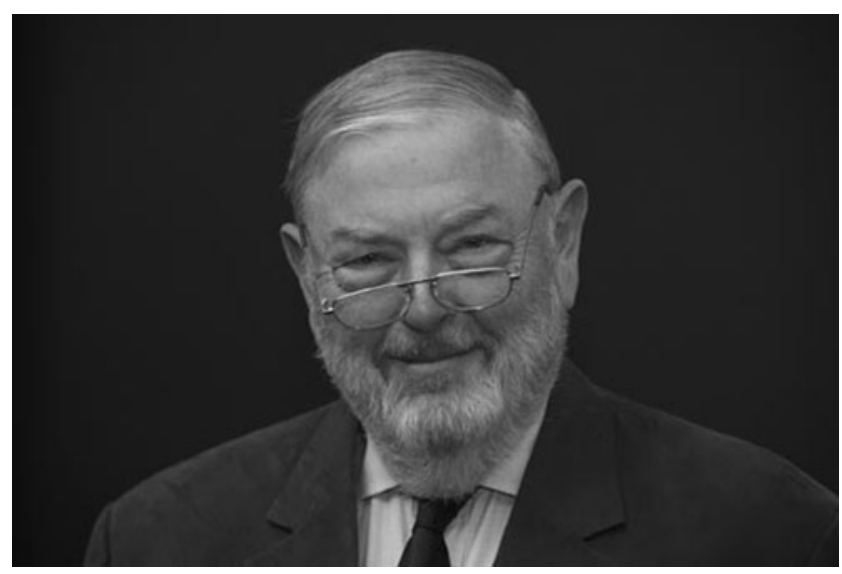


the first of seven children to his mother Ruth Watson, a botanist, and his father, John Francis Funder, a pathologist. The family moved to Melbourne in 1946, when John Funder Senior left the Australian army and joined the Walter and Eliza Institute under Nobel Laureate Macfarlane Burnet.

John W. Funder Junior (henceforth Funder) was educated by Jesuits and was dux of the school and president of his college at the University of Melbourne. Both at school and university, he excelled in debating, but not sport. Funder began the six-year medical course in 1958, but after one week of the third year changed to Honours History and Political Science, to the restrained horror of his parents. Normal transmission was resumed by a return to Medicine in 1962 and graduation 1965. After hospital residence he completed his $\mathrm{PhD}$ in 1969 at the Howard Florey Laboratories and his (postgraduate) MD by thesis in 1970 .

His $\mathrm{PhD}$ thesis was on the role of adrenal steroids in experimental hypertension, and his MD thesis was on the control of aldosterone secretion, areas in which he is still active over 40 years later. His initial postdoctoral appointment was under Dr Isidore Edelman in the Cardiovascular Research Institute at the University of California-San Francisco, from 1970 to 1972, where he did initial studies of mineralocorticoid receptors with David Feldman and began a lifelong friendship with John Baxter until his untimely death in 2011. After a year in Paris at l'Hôpital Necker-more studies on mineralocorticoid receptors and receptor antagonists-he arrived with his family back in Melbourne in 1973 to work under Henry Burger at the Medical Research Centre at Prince Henry's Hospital.

Over the ensuing 40 years, Funder has filled leadership positions nationally and internationally: as President of the Australian Society for Medical Research (the Young Turks) in 1989 (his one-pager in the ASMR Annual Meeting booklet was simultaneously printed as an editorial in Science); in 1982 to 1984 as President of the Endocrine Society of Australia; from 1984 to 2000 as an Executive Member of the International Society of Endocrinology and Chair from 1996 to 2000; from 1990 to 2001 as Director of the Baker Institute in Melbourne; from 2002 as the first non-North American to be elected to the Council of The Endocrine Society, receiving the Sidney H. Ingbar Distinguished Service Award for service to the Society in the same year; and as Chair of the Victorian Health Promotion Foundation (1998-2005) and Sane Australia (1997-2007) and currently as Executive Chair of Obesity Australia (2010-).

More importantly, he has made signal contributions to endocrinology over almost 50 years. He has supervised over $40 \mathrm{PhD}$ students and postdoctoral fellows from the United States, Europe, China, Japan, and Australia. He has published more than 500 peer-reviewed papers over a wide range of areas, from research policy to bioethics, neuroendocrinology to reproductive medicine to hormones and cancer, but consistently and particularly in cardiovascular endocrinologyaldosterone and mineralocorticoid receptors.
With his collaborators he is redefining the pathophysiology of aldosterone and mineralocorticoid receptors, from studies in cells through mice and rats (and sheep) to man. At the clinical level, he chaired The Endocrine Society Task Force on the case detection, diagnosis, and treatment of primary aldosteronism, with Guidelines published in JCEM in 2008, and the Task Force in the process of redrawing the Guidelines.

At the public health level he has emerged as a vocal champion of rewriting the guidelines for treatment of hypertension at presentation to include low-dose mineralocorticoid receptor antagonists as part of first-line therapy; such therapy is vasoprotective in essential hypertension, specific in otherwise resistant hypertension, and game-changing for the $10 \%$ of hypertensives with primary aldosteronism. Why? Because primary aldosteronism has a much higher cardiovascular risk profile than age-, sex-, and blood pressure-matched essential hypertension, and because despite the best efforts of Bill Young and his colleagues around the world. fewer than $1 \%$ of patients with primary aldosterone are ever screened, let alone diagnosed or treated.

Currently, he and his wife Val Diamond live on a small vineyard 30 miles east of Melbourne in the Yarra Valley. Funder has no laboratory, students or fellows, but a series of collaborations in Australia, Europe, and the United States. He is also a prolific writer of opinion pieces, commentaries, and reviews, as well as contributing to data papers. He has referred to The Endocrine Society as his scientific and spiritual home; for over 40 years Funder has made an outstanding contribution to endocrinology, from the laboratory to the clinic, from evolution to public policy. Long may he continue to do so, as a very worthy recipient of the Robert H. Williams Distinguished Leadership Award in Endocrinology.

Anastasia S. Mihailidou

\section{Citation for the 2013 Edwin B. Astwood Award Lecture of The Endocrine Society to Dr Gary D. Hammer}

Gary D. Hammer received his BA in Psychology from the University of Vermont, where he graduated as both the

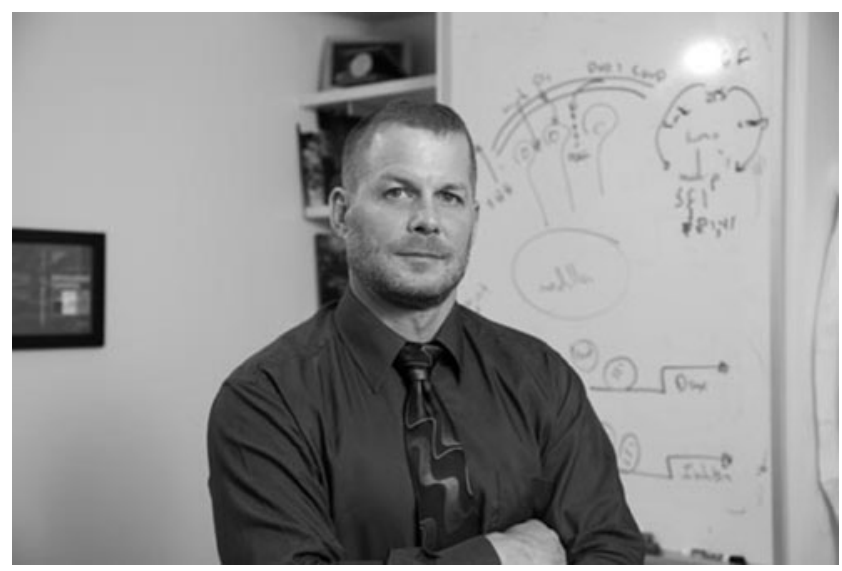


Outstanding Senior and Outstanding Scholar-Athlete. After obtaining his combined MD, PhD under the mentorship Malcolm Low studying ACTH gene transcription at Tufts, he completed his clinical training at University of California San Francisco in Internal Medicine followed by a clinical fellowship in the Division of Endocrinology under John Baxter with the clinical mentorship of J. Blake Tyrrell. As a postdoctoral fellow with Holly Ingraham at the same institution, he studied the regulation of SF1 in adrenal development when he published a seminal paper on SF1 phosphorylation.

As a faculty member at Michigan since 1999, he has studied the biology of adrenal growth and its relations to adrenal cancer. One of his great strengths is the ability to ask the right question and to pursue the answer using whatever technology is most appropriate and informative. Gary is scientifically fearless, routinely employing a combination of molecular biology, cell biology, mouse modeling, genomics, pharmacology, and human clinical studies.

Gary has become a leader in adrenal developmental biology and a major force in endocrinology. Be it at the bench, at the bedside or in between, his research defines the questions, sets the stage for answering them and delivers. His work on mouse SF1 transcriptional regulation revealed cyclic entrainment of transcription that is, in part, regulated by sumoylationdependent inhibition of SF1 phosphorylation. Work on SF1 activity in the adrenal led Hammer to uncover the signaling pathways and transcription factors that dictate the selfrenewal, pluripotency, and fate of subcapsular adrenocortical cells, thereby laying groundwork for the characterization of the stem/progenitor cells of the adrenal cortex. First, in the absence of inhibin and induction of elevated LH, these cells of the adult adrenal cortex differentiated into ovarian lineages replete with follicular structure. Follow-up studies showed that inhibin antagonism of TGF $\beta 2$ signaling in the adrenal is the gatekeeper for adrenal versus gonadal fate. Later studies detailed how the undifferentiated state of this population of cells is maintained by Dax-1, which is activated by Wnt signaling and by glucocorticoids. His work showed that adrenal hypoplasia in patients with Dax-1 mutations is a manifestation of lost progenitor cells. Conversely, constitutive activation of Wnt signaling together with IGF2 resulted in progenitor expansion and the development of adrenal cancer in both mice and people-data that Gary has used to launch national and international clinical trials with IGF receptor inhibitors for adrenal cancer. For these patients, this is the first new therapy in 50 years. Moreover, based on work with colleagues at Michigan on novel adrenolytic compounds, he has founded a biotech company (Atterocor) focused specifically on novel treatments for adrenal cancer.

Gary has served on the Editorial Boards of JCEM, Hormones and Cancer, and Molecular Endocrinology, which honored him as "Outstanding Reviewer," a vivid testament to his diligence and knowledge. He has published 7 papers in
Molecular Endocrinology with multiple papers in $M C B$, Nature, Nature Structural and Molecular Biology, Cancer Cell, Development, and HMG. His seminal reviews in TEM and Endocrine Reviews on adrenal stem cells set the bar for what needs to be done in the field for the next 5 to 10 years.

Gary is a leader in The Endocrine Society, serving as the Chair of the Student Affairs Committee, member of the Direction V Task Force and the Strategic Plan 2 Committee, and is a current member of Council. This year he serves as the inaugural Visiting Professor of The Endocrine Society Ambassador Exchange Program. He has been invited to most of the major symposia where his seminars are legendary for his dynamic style and insightful interface of basic and clinical concepts. He initiated the biennial International Adrenal Cancer Symposia, is on the Organizing Committee of the biyearly Adrenal Cortex Meeting and has been instrumental in coordinating a bona fide international adrenal cancer cooperative group. As an advocate, Gary has worked tirelessly on Capitol Hill, drafting rare cancer legislation introduced in Congress with the staff of the late Senator Ted Kennedy. Somehow he managed to edit the first comprehensive adrenal cancer textbook that again sets the bar for scholarship. The superiority of the Michigan adrenal group is a testament to his leadership and ability to attract the brightest and best scientists to his program. Together with the adrenal team, the center at Michigan has become the leading adrenal cell and developmental biology and adrenal cancer center in the world. For all these contributions, Gary Hammer is a truly deserving recipient of The Endocrine Society's Edwin B. Astwood Award Lecture.

Walter Miller

\section{Citation for the 2013 Clinical Investigator Award Lecture of The Endocrine Society to Dr Steven E. Kahn}

The Endocrine Society is proud to present this year's Clinical Investigator Award Lecture to Steven E. Kahn, professor of medicine at the VA Puget Sound Health Care System and University of Washington. Dr Kahn received his medical school training at the University of Cape Town in South Africa. He immigrated to the United States in 1983 and did his residency in internal medicine at the Albert Einstein Medical Center in Philadelphia, followed by fellowship training in endocrinology and metabolism at the University of Washington in Seattle. He has remained there since and has had a highly successful career in both clinical and basic investigation focused on the pathophysiology of type 2 diabetes.

His delineation in humans of the relationship between insulin sensitivity and insulin release resulted in a paradigm shift in interpreting $\beta$-cell function and helped bring to the fore the critical role of $\beta$-cell dysfunction in disturbances of glucose metabolism. This description provided evidence in humans for a fundamental feature of many endocrine systems, 


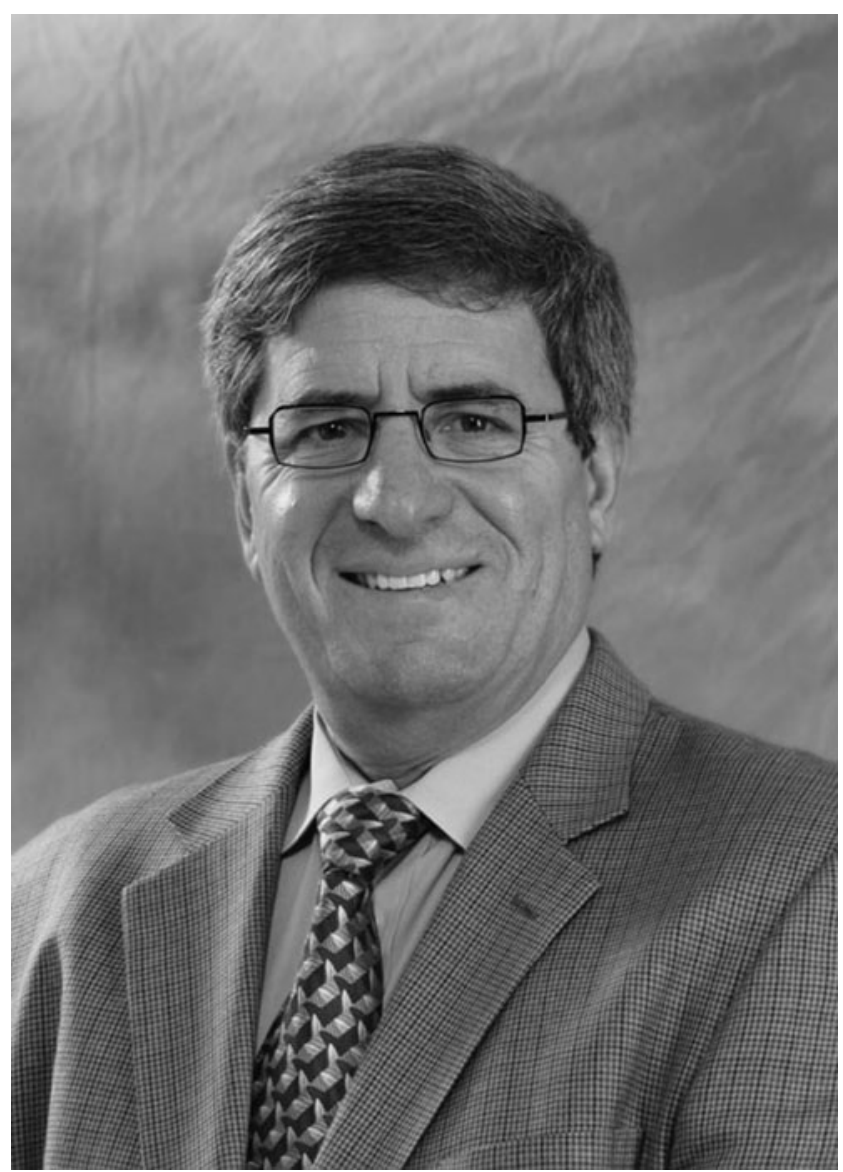

a feedback loop that in this instance underlies the exquisite regulation of glucose metabolism in individuals with marked differences in insulin sensitivity. He followed up this work with studies that clearly defined the natural history of $\beta$-cell dysfunction and its heritable basis. His work has also shown abnormalities of the release of other $\beta$-cell peptides in diabetes and high-risk states, including being first to demonstrate that abnormal proinsulin release is a marker for the subsequent development of diabetes.

His clinical studies have also expanded our understanding of the impact of body fat distribution on metabolism. He helped us further appreciate the importance of the visceral fat depot as a determinant of insulin resistance independent of body mass index, its critical role in determining an adverse lipoprotein profile and the metabolic syndrome, and its interaction with aging in determining changes in $\beta$-cell secretory function. His studies also highlighted the relative importance of the different fat depots in determining levels of adipokines such as leptin and adiponectin and their relationship to a number of metabolic variables.

He has played leadership roles in a number of landmark clinical trials. In the Diabetes Prevention Program (DPP), his background in clinical physiology was tapped for selecting many of the outcome measures. He cochaired A Diabetes
Outcome Progression Trial (ADOPT), which delineated the different long-term effects of glucose-lowering medications on the progressive loss of $\beta$-cell function in type 2 diabetes and first described the increased risk of bone fractures with thiazolidinediones. Most recently, the National Institute of Diabetes and Digestive and Kidney Diseases selected him to chair the Restoring Insulin Secretion (RISE) Study, a multicenter trial that will explore interventions aimed at preserving or recovering islet function in adults and children with prediabetes and early type 2 diabetes.

Dr Kahn has also made complementary use of animal models and in vitro studies to address questions that cannot be directly explored in humans. He was one of the first to develop an interest in islet amyloid as a potential pathogenic mechanism for the loss of $\beta$-cells in type 2 diabetes. He and his colleagues have used different models to examine mechanisms responsible for amyloid formation and its cytotoxicity and have clearly demonstrated that cell damage occurs through the processes of oxidative stress and inflammation that arise during amyloid fibril formation.

He has received numerous awards in recognition of his contributions as a scientist and mentor, including the Novartis Award in Diabetes and the American Diabetes Association Distinguished Clinical Scientist Award. He holds two of his awards very dear. One is the Bernard Pimstone Memorial Lecture of the Society for Endocrinology, Metabolism and Diabetes of South Africa, as it was Bernard Pimstone who first kindled his interest in endocrinology during medical school. The second is the Robert H. Williams-Rachmiel Levine Award, which recognizes his outstanding contributions as a mentor. He is a member of the American Society for Clinical Investigation and the American Association of Physicians.

Aside from his scientific investigation, Dr Kahn has served the community at large. Highlights include membership of the board of directors of the American Diabetes Association and the American Federation for Medical Research, service on The Endocrine Society's Publications Core Committee and a recently completed term as Deputy Editor of The Society's flagship publication, The Journal of Clinical Endocrinology \& Metabolism.

His broad and impactful contributions to our understanding of the pathophysiology and treatment of type 2 diabetes make Steven Kahn a worthy recipient of the Society's highest honor for clinical investigation.

Daniel Drucker

Citation for the 2013 Gerald D. Aurbach Award Lecture of The Endocrine Society to Dr Mitchell A. Lazar

Dr Mitchell A. Lazar is an outstanding and worthy recipient of the 2013 Gerald D. Aurbach Award. Dr Lazar has made seminal discoveries in the area of the nuclear hormone 


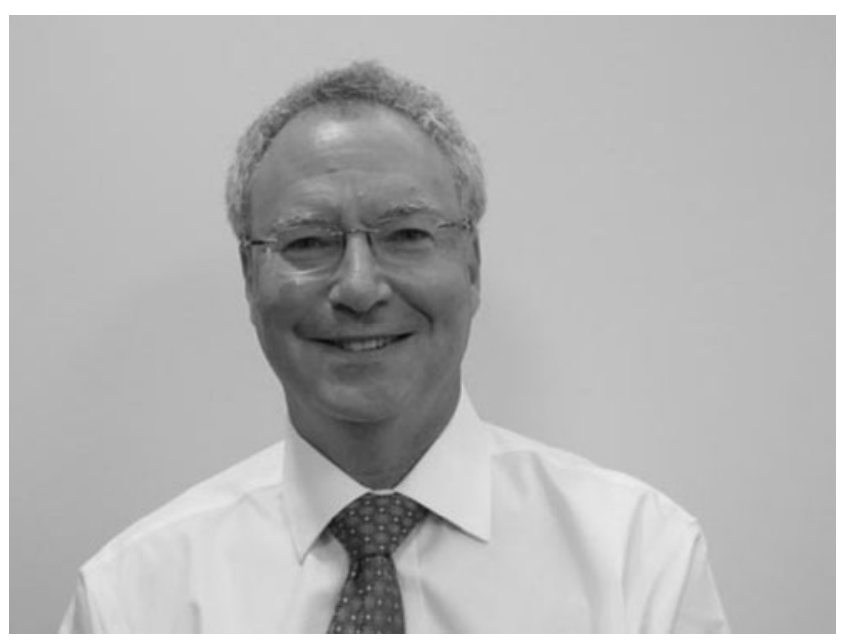

receptors and their coregulators, particularly corepressors. His pioneering studies at the intersection of transcriptional regulatory mechanisms with physiology and metabolism have had a major impact on our understanding of metabolic disease.

Dr Lazar pursued undergraduate studies at MIT, MD/PhD training at Stanford, and residency in Internal Medicine at Brigham and Women's Hospital. His fellowship in Endocrinology at MGH led him to Bill Chin's laboratory at Harvard Medical School, where Dr Lazar began his exploration of nuclear receptor biology with ground-breaking studies on thyroid hormone receptor isoforms and the discovery of the Rev-ErbA $\alpha$ orphan receptor (now called REV-ERB $\alpha$ ).

After joining the faculty at the University of Pennsylvania School of Medicine in 1989, Dr Lazar rose through the ranks to be Chief of the Division of Endocrinology, Diabetes and Metabolism (1996), Director of the Penn Diabetes Center (1998), and founding Director of the Institute for Diabetes, Obesity, and Metabolism (2005). He is currently the Eisman Professor of Medicine and Genetics.

At Penn, the Lazar laboratory has focused on two intertwined topics, the nuclear receptors and their coregulators. Many of his studies have explored the role of PPAR $\gamma$ in adipose tissue and adipogenesis. His was one of two groups who first identified PPAR $\gamma$ as an adipocyte-predominant nuclear receptor, and he has made many contributions to our understanding of the roles of PPAR $\gamma$ in adipogenesis as well as the target of antidiabetic thiazolidinedione (TZD) drugs. Particularly notable was his 2001 discovery of resistin as a new inhibitor of insulin sensitivity expressed in adipocytes and suppressed by TZDs. More than 2000 publications later, resistin continues to attract attention, as well as some controversy, particularly since in humans resistin is secreted predominantly by macrophages rather than adipocytes. Larger scale assessments of its impact in human diabetes and other diseases have reinforced its potential role as a link between inflammation and metabolic disease.

In 1999 the Lazar group identified a conserved motif in corepressors NCoR and SMRT that mediates their interaction with nuclear receptors. The surprising but clear similarity of this element, which he termed the CoRNR ("corepressor/ nuclear receptor") motif, with the analogous coactivator motif revealed an unexpected link between the mechanisms of transcriptional repression and activation. An elegant series of further experiments unraveled the mechanisms of transrepression by NCoR, as mediated by its interaction with and direct enzymatic activation of the histone deacetylase HDAC3.

The enigmatic quote that "things that go around come around" may have been meant to describe the recent trajectory of two of Dr Lazar's interests, NCoR/HDAC3 and REV-ERB $\alpha$. In 2007, he showed that that heme is a functional ligand for $\mathrm{REV}-\mathrm{ERB} \alpha$ and defined its potential for metabolic impact in the liver. In another elegant series of subsequent studies, the Lazar group described the striking circadian interactions of REV-ERB $\alpha$ (and $\beta$ ) with NCoR and HDAC3 in the liver that result in a daily epigenomic cycle regulating liver metabolism. In this cycle, the REV-ERBs act during the day, when mice are inactive, to recruit the repressive NCoR/HDAC3 complex to a network of genes required for fatty acid synthesis, shutting down the process of lipogenesis when it is not needed for energy storage. Dysregulation of this lipogenic shutdown results in a dramatic increase in hepatosteatosis. Yet, despite the fatty liver, mice lacking HDAC3 are insulin sensitive, thereby overturning the general view that fatty liver invariably causes insulin resistance. Dr Lazar has shown that this is due to metabolic substrate rerouting, which is normally circadian due to the REV-ERB rhythm, but becomes locked into lipid storage and sequestration mode when this is disrupted.

In the course of this remarkable body of work, bridging the fields of Endocrinology and Metabolism, Dr Lazar has been an outstanding mentor for a number of very successful trainees. The impact of his accomplishments has been recognized by numerous special lectures and awards, including election to the American Society for Clinical Investigation, the Association of American Physicians, the Institute of Medicine of the National Academy of Sciences, and the American Academy of Arts and Sciences. The 1990 Nichols New Investigator Award from The Endocrine Society and 1994 Van Meter Prize and Lecture from the American Thyroid Association were followed by the 2006 Edwin B. Astwood Lecture Award from The Endocrine Society. The current Gerald D. Aurbach Award is certainly a very fitting addition to this impressive list.

David Moore

Citation for the 2013 Sidney H. Ingbar Distinguished Service Award of The Endocrine Society to Dr Irving M. Spitz

Irving M. Spitz, in partnership with prior Ingbar Award winner Wayne Bardin, completed the herculean task of 


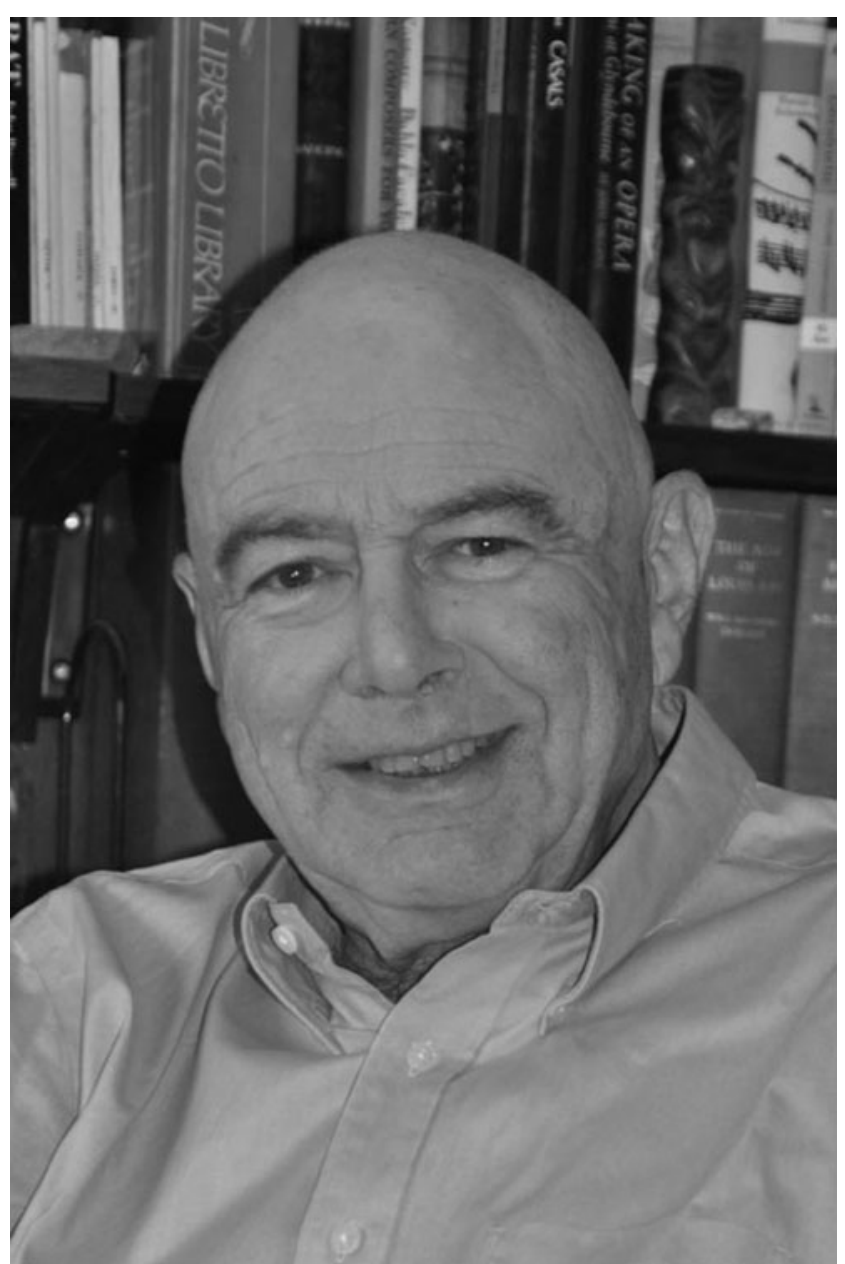

introducing Roussel-UCLAF's progesterone receptor antagonist RU486 (mifepristone) into the United States for clinical use, despite antiabortion rhetoric (and potential violence). They completed toxicity studies and, with Spitz in the lead, skillfully organized the delicate and sensitive US clinical trials that proved the efficacy and safety of the combination of RU486 plus prostaglandin for termination of pregnancy. Because of the FDA's reputation, approval for this regimen in the United States also led to the swift spread to nations around the world. Studies conducted by Irving M. Spitz and the group at the Population Council also demonstrated that effective anti-progestational doses of mifepristone did not cause adrenal insufficiency and clarified the complexities of the drug's metabolism. They also demonstrated the long-term safety of RU486 and its multiple effects on the endometrium and showed that this drug and other progesterone receptor modulators have potential applications as contraceptives and in the treatment of myomas, endometriosis, and dysfunctional uterine bleeding as well as possible use in meningiomas, breast cancer, and other malignancies. The anti-progestin therapy introduced by Irving M. Spitz (together with Wayne Bardin and their teammates) has opened a new chapter in female reproductive endocrinology, one of the 20th century's most important services to women's health.

Born in South Africa, Irving M. Spitz received his MB, BCh (MD equivalent), the Abelheim medal, $\mathrm{MD}$ ( $\mathrm{PhD}$ equivalent) and DSc from Johannesburg's Witwatersrand University. In 1970, he completed an endocrine fellowship in Jerusalem with the late David Rabin, where he pioneered studies with gonadotropin-releasing hormone $(\mathrm{GnRH})$, described the heterogeneity of isolated gonadotropin deficiency (IGD), and documented the first woman with isolated FSH deficiency.

Irving directed the Endocrinology Department at Jerusalem's Shaare Zedek Medical Center from 1977 to 1982. With a talented group of investigators, he continued studies in reproductive endocrinology, demonstrating the prolactin deficiency with IGD was a consequence of the low steroid milieu and described the first patient with isolated prolactin deficiency. In 1980, he was a Fogarty Fellow in the NIH's Diabetes Branch with Jesse Roth.

He was recruited by Wayne Bardin as a Senior Scientist of the Population Council in New York (1983-2002). There, in addition to his work on RU486, Irving was a member of the team developing delivery systems for reproductive health and cancer. He organized numerous multicenter trials and supervised multiple laboratories around the world. He was a key player in elucidating the mechanism of action of GnRH agonists and antagonists, including their potential for contraception and for acute intermittent porphyria.

Irving returned to Jerusalem in 1995 to found the Institute of Hormone Research at Shaare Zedek Medical Center. His team pioneered the use of a hydrogel implant releasing the GnRH agonist, histrelin, in children with central precocious puberty, which greatly simplified treatment and improved their quality of life.

A member of The Endocrine Society since 1974, Irving was elected to the American Society for Clinical Investigation in 1984 and elected a Fellow of the Royal College of Physicians of London in 1997. He has authored 232 publications (mostly in peer-reviewed journals including 11 in The New England Journal of Medicine) as well as books, book chapters, and regular contributions to UpToDate. In addition to being an invited keynote speaker at numerous conferences, Irving has organized several highly successful international meetings on progesterone antagonists. He has served as mentor to numerous graduate level students, many of whom have gone on to occupy prestigious academic positions throughout the world. Today, he is Professor Emeritus of Endocrinology at Ben Gurion University of the Negev in Israel and Adjunct Professor of Medicine at Weill Cornell Medical College.

Beyond medicine and science, Irving is a Renaissance scholar, awesome and modest in his extraordinary knowledge and appreciation of music (especially opera), art, history, photography, archeology, and cartography of the Holy Land. He is the Music Editor of a New York based publication 
and frequently contributes articles and reviews on travel and culture to The Jerusalem Post as well as several other international publications. His photographs will be included in the forthcoming Oxford Encyclopedia of the Bible and Archeology.

Irving is an inspiration to others-for his integrity, commitment to medicine, empathy for patients and colleagues and dedication to friends and family. Irving and his wife Diane especially enjoy time with their children and grandchildren.

For all of his accomplishments, especially those related to reproduction in humans, The Endocrine Society is pleased to bestow the 2013 Sidney H. Ingbar Distinguished Service Award on Irving M. Spitz.

Jesse Roth and Bert O'Malley

Citation for the 2013 Roy O. Greep Award Lecture of The Endocrine Society to Dr Donald P. McDonnell

Dr Donald P. McDonnell has made remarkable contributions by elucidating the complex pharmacology of nuclear hormone receptors that have enabled the discovery of novel therapeutics targeting nuclear receptors or their obligate

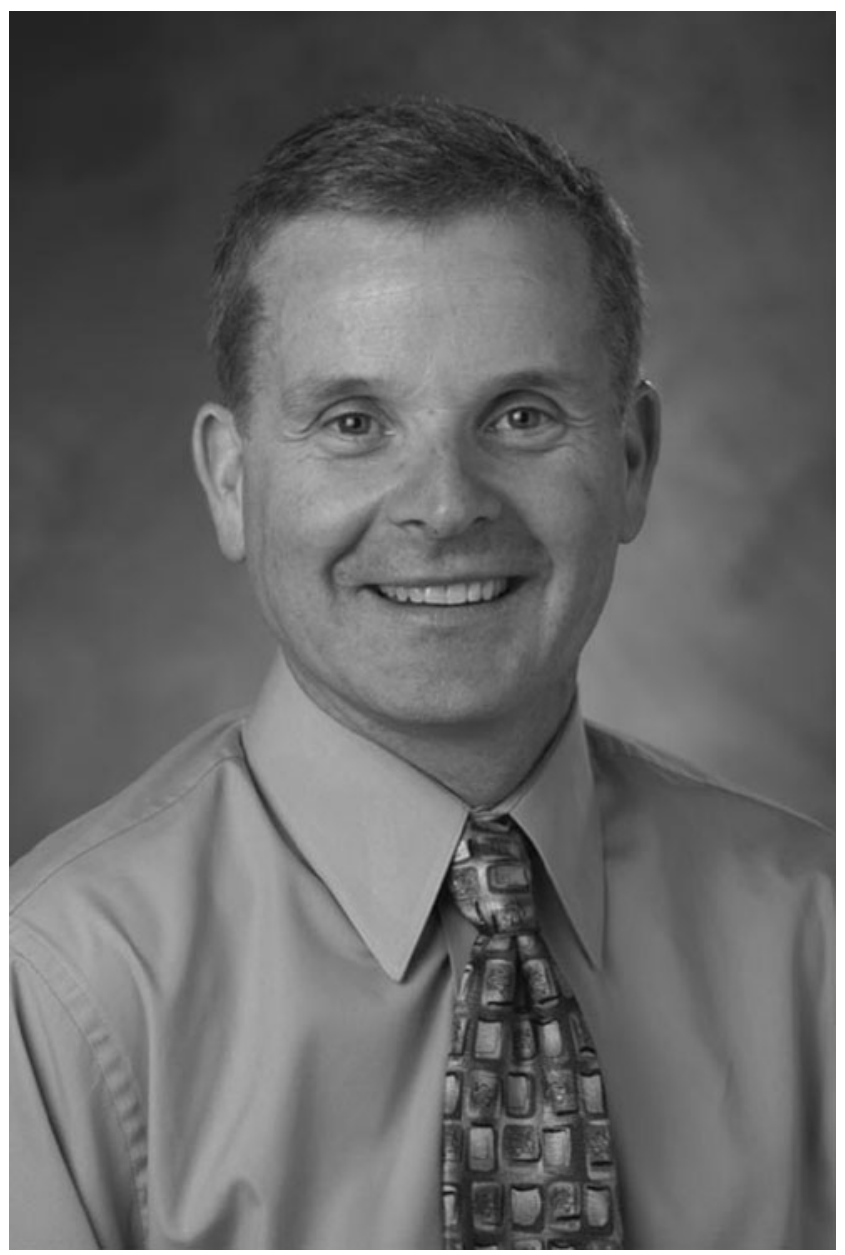

cofactors to achieve selective regulation of critical endocrine physiological and pathological processes. In pioneering the pharmacological exploitation of nuclear receptors as therapeutic targets, his work has led to the discovery of important drugs that modulate estrogen receptor, androgen receptor, and orphan nuclear receptors in unique ways to achieve optimal tissue-selective actions of these receptors in bone, cardiovascular, and reproductive tissues.

Dr McDonnell is currently Glaxo-Wellcome Professor of Molecular and Cellular Biology and Chairman of the Department of Pharmacology and Cancer Biology at Duke University School of Medicine. He is also Associate Director for Basic Research at the Duke Cancer Institute. Dr McDonnell received his $\mathrm{PhD}$ degree from the Department of Cell Biology at Baylor College of Medicine with Bert O'Malley and then joined the faculty at Baylor before becoming Director and Head of Molecular Biology at Ligand Pharmaceuticals. He joined Duke University Medical Center in 1994 and quickly rose through the ranks to his current positions.

Donald McDonnell has taken broad and innovative approaches that have provided a firm mechanistic basis for the development of optimal selective receptor modulators, including selective estrogen receptor modulators (SERMs) and selective androgen receptor modulators (SARMs). He has shown that nuclear receptors can adopt a spectrum of conformations that reflect the structure of their ligands and that these conformations regulate differential interactions with coregulators and engender the spectrum of tissue-specific activities of agonist or antagonist ligands. His work is widely recognized as providing the basis for understanding the distinctive biology of SERMs and SARMs in diverse receptor target tissues. His research group has also spearheaded the development of a new class of nuclear receptor antagonists that function by directly targeting receptor-coregulator interactions. Using combinatorial peptide phage display to develop probes whose binding characteristics reflected the overall shape of the receptor, the McDonnell laboratory was able to show that ligand-induced changes in nuclear receptor conformation engendered the recruitment of functionally distinct cofactors and that disruption of these protein-protein interaction sites altered the pharmacology of nuclear receptors including the estrogen, androgen, progesterone, and vitamin D receptors. These receptor and receptor ligand screens that incorporated his insights on the relationship between receptor conformation and activity resulted in the discovery of several SERMs that are currently used for the prevention and treatment of osteoporosis, as well as ligands found to be extremely effective in models of tamoxifen-resistant breast cancer that are now undergoing clinical development as a treatment for invasive breast cancer.

His work on the important relationship between receptor conformation, differential cofactor recruitment, and pharmacological activity was subsequently applied to androgen receptors 
and led to the identification of new classes of SARMs whose prostate-sparing anabolic activities are likely to have clinical utility in the treatment of various muscle wasting syndromes. The power of this mechanism/cofactor-based approach was also apparent in the identification of a new class of androgen receptor antagonists that bound outside the ligand binding pocket of the receptor and allosterically interfered with cofactor binding, which might prove useful in treatment of certain advanced forms of castration-resistant prostate cancer.

The McDonnell laboratory has also defined new roles for orphan nuclear receptors, focusing on estrogen related receptor- $\alpha(E R R \alpha)$ and its actions in metabolic homeostasis and breast cancer pathogenesis. In a series of recent, elegant studies, the McDonnell laboratory has provided compelling evidence that $\mathrm{ERR} \alpha$ and its obligate coregulator, $\mathrm{PGC}-1 \beta$, are causally involved in breast tumorigenesis and that inhibition of tumor growth can be achieved with ablation of this receptor. They have also identified a series of known drugs that inhibit this receptor by interfering with the activity and/or expression of its obligate coregulator, highlighting a promising treatment strategy for these aggressive breast cancers for which there are currently only limited therapeutic options.

Donald McDonnell's remarkable contributions in delineating the pharmacology of nuclear hormone receptors have provided the foundations for the discovery of novel therapeutics that regulate nuclear receptors or their obligate cofactors in unique ways so as to selectively modulate critical endocrine physiological and pathological processes. He is a truly outstanding scientist, as well as an inspiring lecturer. His exceptional contributions to endocrinology through mechanistic insights and the translation of these into the development of important therapeutics have had a major impact and make him a highly deserving recipient of the 2013 Roy O. Greep Lecture Award of The Endocrine Society.

Benita Katzenellenbogen

\section{Citation for the 2013 Distinguished Educator Award of The Endocrine Society to Dr Mark E. Molitch}

Dr Mark E. Molitch, Professor in Medicine, Endocrinology, Diabetes and Metabolism at Northwestern University, has dedicated his life to communicating new advances in the field of endocrinology and optimal patient care to educate students, house staff, fellows, and colleagues through his lectures and writing. Mark attended and completed his undergraduate training at Princeton University and then attended the University of Pennsylvania for medical school. Under Bill Odell's tutelage at Harborview, he trained in Endocrinology. He was a junior faculty member at Tufts for nine years before being recruited to Northwestern University where he rose through the ranks to become a Professor in Medicine in 1989.

Mark is unique in that he is an international thought leader in both the areas of pituitary disease and diabetic kidney

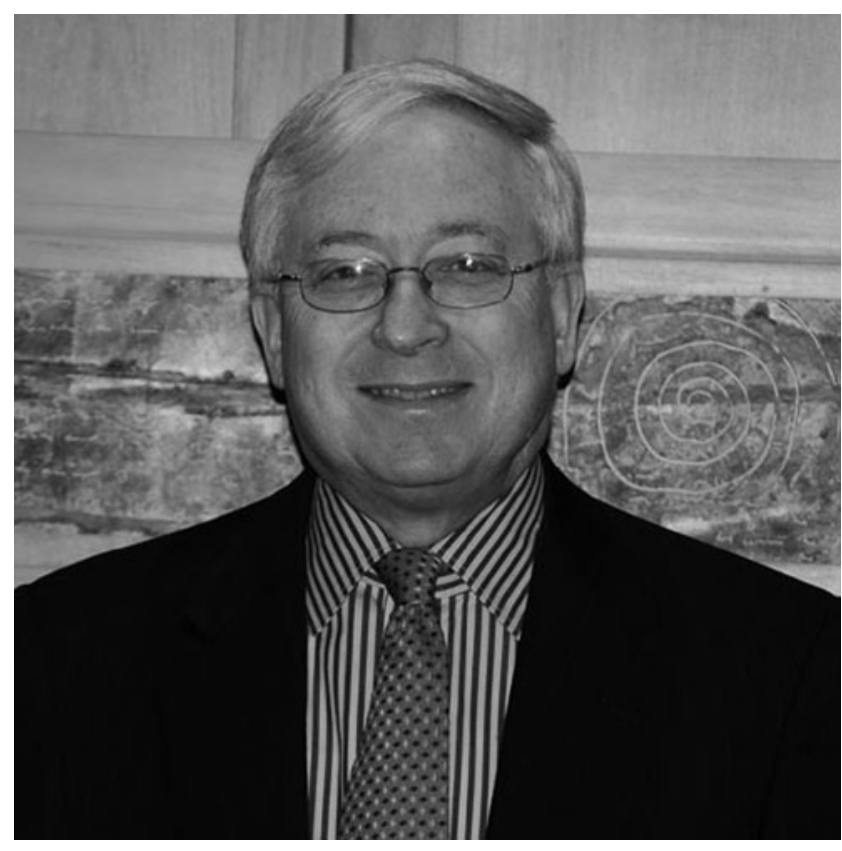

disease. As a clinical investigator and educator, he has published over 125 original articles and over 200 reviews and book chapters. Dr Molitch is a sought-after international speaker, including being the British Endocrine Society's Clinical Endocrinology Trust Visiting Professor in 2009.

For The Endocrine Society, Mark chaired the very first Endocrinology Self-Assessment Program, which was a combined effort of The Endocrine Society, the American Diabetes Association, and the American College of Physicians. He has been instrumental in many Endocrine Society guideline committees, including Adult Growth Hormone Deficiency, Acromegaly and the Management of Pituitary Incidentalomas. $\mathrm{He}$ also chaired the Guideline for the Management of Prolactinomas of The Pituitary Society. Importantly, he has recently overseen the growth of new educational formats as the Chair of Clinical Endocrinology Update, expanding the educational opportunities for clinicians in practice.

Many in The Society are not aware of Mark's parallel accomplishments in diabetes. He was on the committee who wrote the very first American Diabetes Association Standards of Care and then chaired that committee when they incorporated evidence grading to improve clinical care and was the American Diabetes Association representative to the National Kidney Foundation's KDOQI Guideline for the Management of Diabetic Kidney Disease. He also was awarded the Outstanding Physician Educator Award of the American Diabetes Association in 1997. He may be the first person to be given such awards by both the American Diabetes Association and The Endocrine Society.

In addition to these many educational activities, Mark serves the international community in his role as the Founder and Director of a primary care clinic for the 
underserved in the remote rainforest of Bolivia, along with his wife Dr Susan Hou, a nephrologist at Loyola University Medical School in Chicago. Not only does this clinic provide free medical care for the indigent, it also serves as an accredited International Health Rotation for medical students and house officers from the Chicago area. More than 100 students and residents have been educated in international health at the clinic over the past 12 years.

Thus, for a lifelong commitment and dedication to the education of his peers, clinical providers and patients, The Endocrine Society recognizes Mark E. Molitch with the Distinguished Educator Award.

Margaret Wierman

Citation for the 2013 Distinguished Physician Award of The Endocrine Society to Dr Michael T. McDermott

Michael T. McDermott, MD, is widely known for the breadth of his mastery in the broad field of endocrinology and diabetes. He graduated from the Georgia Institute of Technology Summa Cum Laude and was an Alpha Omega Alpha graduate from Tulane Medical School. Internal Medicine training and an Endocrinology fellowship were obtained at the Fitzsimons Army Medical Center in Aurora, Colorado. During his service in the US Army at Fitzsimons, he was Chief of Endocrinology and Director of the Endocrinology Training Program. He was awarded the coveted Peter Forsham Award for Military Endocrinology and on two occasions given the George Washington Honor Medal. Between 1994 and 1997 he was the Endocrinology Consultant to the Surgeon General. Upon retiring from active duty in the Army in 1997, Dr McDermott was recruited to the University of Colorado, School of Medicine, as Professor of Medicine and Director of the Endocrinology and Diabetes Practice, a position he has held for the last 16 years. In 2005, he developed and continues to direct the Diabetes Program at the University of Colorado Hospital.

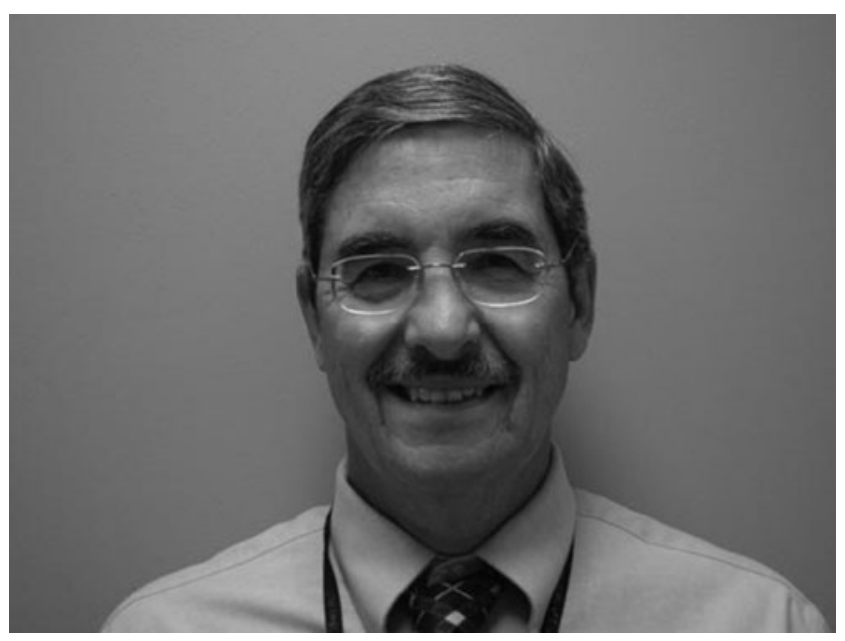

Dr McDermott's scholarship is one of curiosity; the ability to take observations at the bedside and discover prevalence, pathophysiology, and impact. An example came early in his career when he was one of the first to recognize that radioactive iodine therapy of hyperthyroidism could induce, on occasion, the surprising and unexpected development of "thyroid storm." He also recognized that the common flu shot could uncommonly be followed by severe subacute thyroiditis and that lithium therapy could have untoward effects on the thyroid gland including not only hypothyroidism but also hyperthyroidism. Upon joining the Endocrinology Division at the University of Colorado as a full professor, Dr McDermott made a rather surprising decision when he declared, "I want to learn about molecular biology." When asked "Why?" he answered simply, "I want to know the basis of disease." Thus, the retired full army colonel went to the bench late in the afternoons after a full day in the clinic, staying into the night and during weekends to learn techniques in molecular biology. This resulted in 6 papers in The Journal of Biological Chemistry, Molecular and Cellular Endocrinology, Pituitary, and Thyroid.

Dr McDermott is an outstanding educator. He has that rare ability to take complicated topics in thyroid, bone mineral metabolism, and diabetes and present them with not only clarity but also excitement and novelty. One striking example is the annual Endocrine Fellows Course that is given prior to the American Thyroid Association Meeting. The course directors needed a talk on the genesis of cancer but could not identify an oncologist to give the talk. Dr McDermott offered that he would "give it a try; I need to know about that." The product was the famous "Thyroid Oncogene" talk which nearly all clinical endocrinology fellows have heard in an annually updated version. He has won numerous teaching awards and gives generously of his time to lecture not only at large national meetings but also locally and rurally wherever there are needs and gaps in education.

If Dr McDermott has a "signature" literary product, it would be his book, Endocrine Secrets. This extraordinarily useful handbook was first written in 1995 and the 6th edition was published in 2013. It is both comprehensive and laced with the perspectives of experts in the field. Dr McDermott has guided its creation and nurtured its development. This 18 -year effort exemplifies both a deep and broad academic career; one that surely deserves the accolade of Distinguished Physician. When ending a lecture, Mike always closes with a familiar quotation from the legendary distance runner Steve Prefontaine, a quote which in fact characterizes Dr Michael T. McDermott himself: "To give anything less than your best is to sacrifice the gift."

E. Chester Ridgway

\section{Citation for the 2013 Richard E. Weitzman Memorial Award of The Endocrine Society to Dr Tony K. T. Lam}

Tony K. T. Lam, PhD, is the John Kitson McIvor (19151942) Endowed Chair in Diabetes Research, Canada Research 


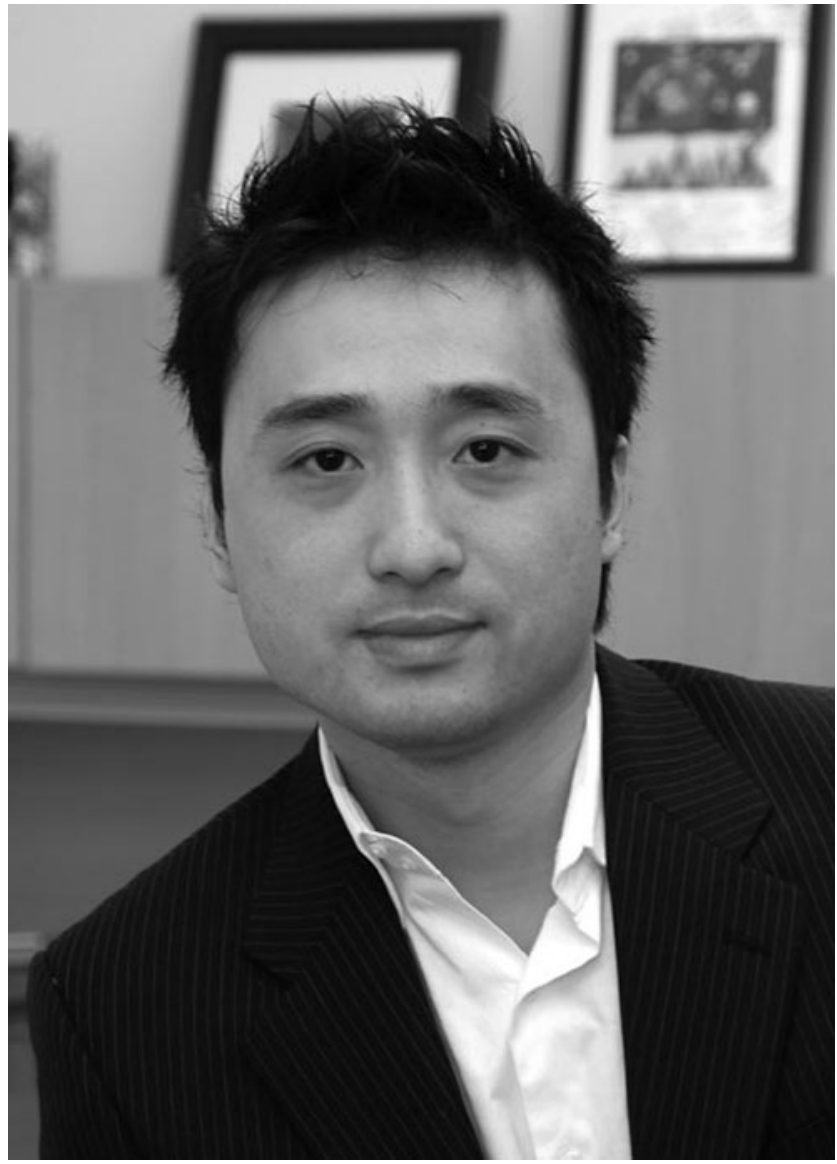

Chair in Obesity and Associate Professor of Physiology and Medicine at the Toronto General Research Institute and the University of Toronto. He is also Associate Director of Research at the University of Toronto Banting and Best Diabetes Centre. Dr Lam received his PhD degree from the University of Toronto, working in the laboratory of Adria Giacca (1998-2003) and did postdoctoral training at the Albert Einstein College of Medicine in New York (20032006). He was recruited back to Toronto in 2006.

Tony began his research career by demonstrating as a graduate student that lipids activate hepatic $\mathrm{PKC} \delta$ to induce insulin resistance As a postdoctoral fellow in the laboratory of Luciano Rossetti, he carried out seminal studies establishing a brain-liver axis that mediates the hypothalamic control of hepatic glucose and lipid production in rodents. He along with his colleagues demonstrated that the hypothalamus senses circulating lipids, glucose, insulin, and resistin to regulate glucose production. In parallel, hypothalamic nutrient sensing regulates hepatic triglyceride-rich VLDL secretion. His research as a trainee unveiled novel signaling molecules in the hypothalamus and the liver that regulate glucose and lipid production.

Soon after his return to Toronto, Lam's laboratory began elucidating the role of a novel neurohumoral signaling pathway connecting gut, brain, and liver, which plays a critical role in glucose homeostasis. After making the initial observations that lipid sensing in the gut triggers a gut-brain-liver axis to lower hepatic glucose production, the Lam laboratory has systematically dissected the role of duodenal PKC $\delta$ and cholecystokinin signaling in mediating this glucoregulatory effect of duodenal lipid sensing. Importantly, direct activation of duodenal lipid-PKC $\delta$-cholecystokinin signaling fails to lower glucose production in high-fat fed rodents. Further evidence indicates that duodenal cholecystokinin resistance partly lies in the inability of cholecystokinin to activate PKA since direct duodenal PKA activation is necessary and sufficient to lower glucose production in high-fat fed rodents. Dr Lam has also shown that jejunal nutrient sensing activates a neuronal network to lower glucose production in normal rodents and is necessary for bariatric surgery to rapidly lower glucose levels in uncontrolled diabetes independently of weight loss. These findings collectively indicate that targeting duodenal and/or jejunal signaling molecules may have therapeutic potential in lowering blood glucose levels in diabetes and obesity.

The Lam laboratory in parallel has revealed novel nutrientsensing mechanisms in the dorsal vagal complex that regulate hepatic glucose production and triglyceride-rich VLDL secretion. They demonstrated that direct activation of $N$-methyl-daspartate receptors in the dorsal vagal complex by the amino acid glycine is sufficient to lower glucose production and triglyceride-rich VLDL secretion in both normal and highfat fed rodents. In addition, activation of $N$-methyl-d-aspartate receptors in the dorsal vagal complex is necessary for nutrient sensing mechanisms in the hypothalamus or the intestine to regulate glucose production. Lam's research here suggests that targeting $N$-methyl-d-aspartate receptors in the dorsal vagal complex (via glycine or a glycine analog) may lower blood glucose and lipid levels in diabetes and obesity.

Finally, the Lam laboratory has characterized a novel insulin signaling pathway in the dorsal vagal complex that regulates glucose production. Dr Lam demonstrated that insulin signals through a PI 3-kinase-independent but Erk1/2-dependent pathway to activate ATP-sensitive potassium channels in the dorsal vagal complex to lower glucose production in rodents. Importantly, insulin signaling in the dorsal vagal complex fails to lower glucose production in high-fat fed rodents, revealing a novel site of insulin resistance in diet-induced obesity.

In summary, the Lam laboratory has greatly advanced our understanding of how the gut communicates with the brain to regulate metabolism. Dr Lam has identified novel therapeutic targets in the gut and the brain to lower blood glucose and lipid levels and body weight in experimental models of diabetes and obesity. Tony's impressive accomplishments make him a well-deserved recipient of the Richard E. Weitzman Award.

Gary Lewis 
Citation for the 2013 International Excellence in Endocrinology Award of The Endocrine Society to Dr Berenice de Mendonça

This new Endocrine Society Laureate Award recognizes exceptional contributions to endocrinology either internationally or in the recipient's home country. The awardee's contributions may encompass one or more areas of research, endocrine education, clinical practice, and administration.

It is with great pleasure that I introduce Dr Berenice de Mendonça for the inauguration of this important distinction. Berenice is one of those rare individuals who can claim major contributions to world endocrinology in all aspects for which this prize can be considered: research, endocrine education, clinical practice, and administration.

Professor de Mendonça is currently the Head Professor of the Endocrinology and Metabolism Division of the School of Medicine at São Paulo University and one of the pioneers of translational molecular endocrinology. She has had a strong interest in the genetic and molecular basis of many aspects of endocrinology, such as disorders of sex development, adrenal tumors, puberty disorders and pituitary dysfunction over many years. Her publication record speaks for itself, both in terms of her laboratory's original research as well as collaborations with

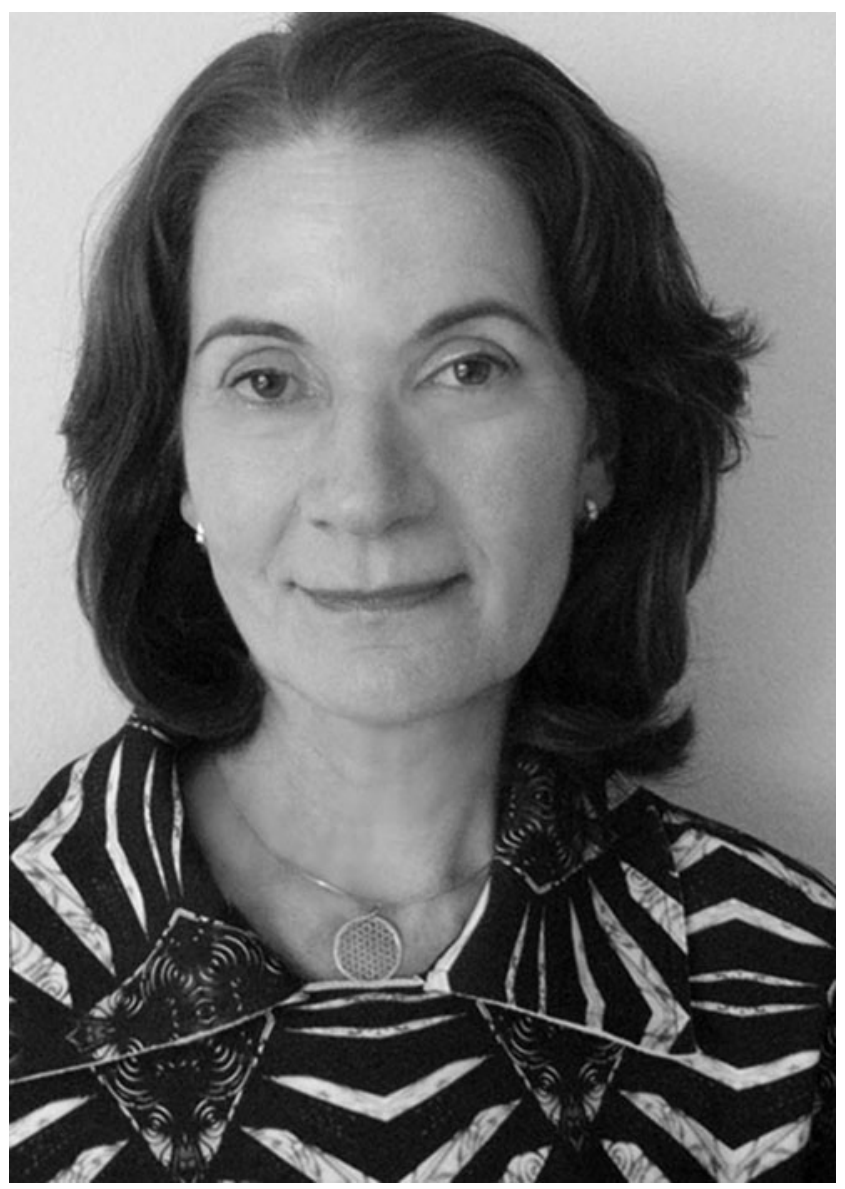

leading research groups around the world. As an outstanding international investigator of disorders of sex development, she is among the top scientists in this field according to ISI Web of Knowledge. Indeed, her clinical expertise has been recognized by several invitations to serve on international consensus groups on disorders of sex development, and seminal publications in The Journal of Clinical Investigation, Nature Genetics, and The New England Journal of Medicine attest to her successful career as a clinician scientist.

Despite her commitments, Berenice remains focused on clinical medicine and is very engaged with her clinical practice. She has a great skill at linking clinical and endocrine phenotypes with potential novel mechanisms of disease, always maintaining a keen interest in research that leads to patient benefit. She exemplifies the ultimate challenge in clinical medicine, namely the capacity for making observations in individual patients that can lead to the improved care of other individuals with the same disorder.

Professor de Mendonça is also a very effective administrator. She was awarded full Professor of Endocrinology at University of São Paulo School of Medicine in 2005 and was Clinical and Academic Lead in endocrinology at this Institution for several years. More recently she has also led the Department of Medicine. Adding to all these, her achievements in establishing a world-class hormonal and molecular laboratory within the public health sector in Brazil have been remarkable. Another important accomplishment was to create and coordinate a unique and pioneering multidisciplinary group in Brazil and in Latin America for the assistance and research of sex disorders.

Berenice is a true mentor for many students and fellows who have passed through her research and clinical teams. She has trained a generation of academic staff, having supervised five MSc and an astonishing $22 \mathrm{PhD}$ students and trained many residents and fellows. Most of her students have been very successful, progressing through the ranks of the University of São Paulo or becoming established clinicians and researchers throughout Brazil. Several of her students hold high-ranking faculty places, such as Ana Claudia Latronico, a full professor in Endocrinology at the same University and a previous Richard E. Weitzman The Endocrine Society Laureate Awardee. Berenice is also known to have has a powerful gift of attracting young trainees. You will always find her surrounded by them. Her talks are usually standing room only, full of young students hanging onto her every word!

Because of her whole body of work, she has received many awards and international distinctions. She has recently been awarded the Clinical Endocrinology Trust Medal from the Society for Endocrinology in the UK, The Brazilian Endocrine Society Award for outstanding research in Endocrinology and the Scopus 2009 Award given by Elsevier and The Brazilian Education Ministry in recognition of outstanding contributions to Medicine and Education. 
Berenice de Mendonça is a quintessential leader-role model whose lifetime work bridges basic science, clinical investigation and practice, endocrine education, and administration. This distinction acknowledges the important impact of the legacy of her contributions and of the bridges built among many countries and continents.

Valéria Guimarães

Citation for the 2013 Outstanding Clinical Practitioner Award of The Endocrine Society to Dr Steven B. Nagelberg

Dr Steven Nagelberg is a superb choice for recipient of The Endocrine Society's inaugural Outstanding Clinical Practitioner Award that recognizes clinical practitioner members of The Endocrine Society who have made extraordinary contributions in medicine and to the public.

Dr Nagelberg has spent most of his life on the east coast. He was born in Hollywood, Florida, not to be confused with the city of stars in California. He attended Bucknell University where he starred in track (as a half-miler) and excelled as a student. After completing just three years at Bucknell, he was accepted early to the Columbia University College of Physicians \& Surgeons where he also excelled and was elected to the Alpha Omega Alpha Honor Society. After graduating from Columbia P \& S in 1978, Dr Nagelberg completed his internship/residency in internal medicine at the University of California at San Francisco. Following residency, he remained as faculty in general medicine before returning to the east coast to complete a three-year fellowship in Endocrinology and Metabolism in the Clinical Endocrinology Branch, National Institute of Arthritis, Diabetes, Digestive, and Kidney Diseases, National Institutes of Health, in Bethesda, Maryland. He completed his fellowship

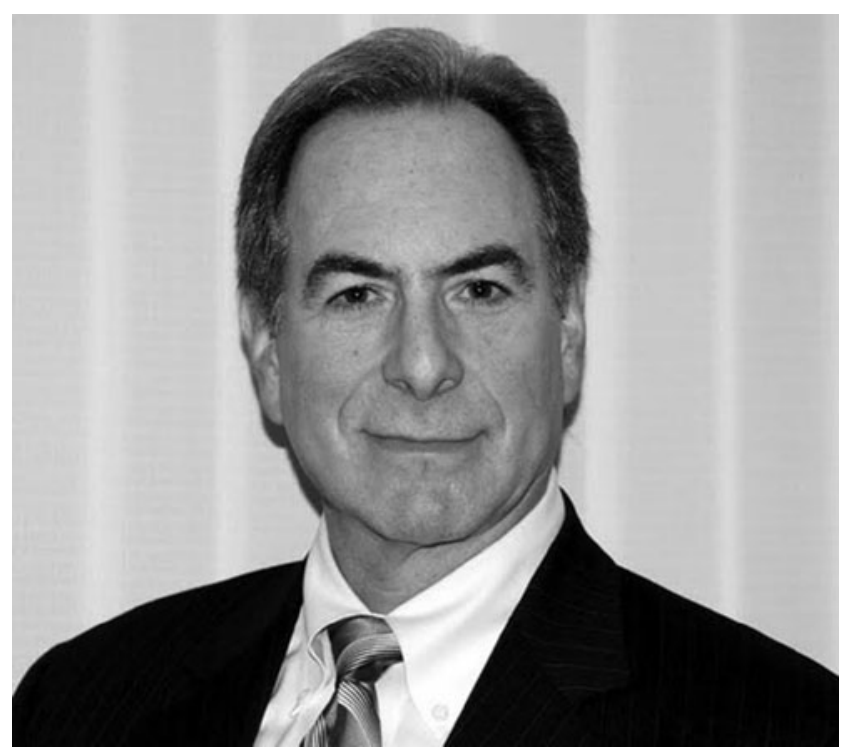

in 1985 and was recruited to the Division of Endocrinology and Metabolism as Assistant Professor of Medicine at Thomas Jefferson University in Philadelphia, Pennsylvania. He decided to pursue a career in clinical practice in 1987 and was appointed Assistant Professor of Medicine in the Division of Endocrinology and Metabolism at the Medical College of Pennsylvania (formerly known as Women's Medical College of Pennsylvania). He was a key faculty member for the endocrinology fellowship program for years at Medical College of Pennsylvania. In fact, two of his former fellows are now in practice with him. After Medical College of Pennsylvania and Hahnemann Medical College merged in 1993 to form the Drexel University College of Medicine, Dr Nagelberg was appointed Clinical Professor of Medicine, a title he continues to hold. He has authored or coauthored 16 original research articles, case reports, chapters, and reviews.

$\mathrm{He}$ is widely known in the Philadelphia medical community for his clinical expertise. His peers have voted him as one of Philadelphia Magazine's "Top Docs" 11 times over the past two decades. In 2012, he was named as a Philadelphia "Super Doc." He has also been recognized repeatedly as one of America's "Top Physicians" by the Consumers' Research Council of America. Dr Nagelberg has been President and managing partner of Endocrine Metabolic Associates, the Delaware Valley's largest private endocrinology group practice, since 1991. His patients adore him. One patient commented, "For years I have driven from New Jersey to Philadelphia to see Dr Nagelberg. No matter what question or problem you may have, he takes his time with you. That is very important. A lot of places rush you in and out. They don't really care about you as a person, where Dr Nagelberg does. You can definitely trust him." Another patient wrote, "I have been seeing Dr Nagelberg for years. He is the most caring man who gives as much time to his patients as he possibly can. $\mathrm{He}$ is very knowledgeable. I have never met anyone so caring and understanding."

Dr Nagelberg has served as Section Chief, Metabolic Diseases and Endocrinology at the trihospital Aria Health system for the past 22 years. He received that institution's "Dedication to Teaching Award" in 2006. He is principal investigator for clinical research trials conducted in his office. He has been an almost constant contributor to the American Board of Internal Medicine for the past 22 years, having served six years as Physician-Secretary for the Endocrinology, Diabetes and Metabolism Subspecialty Board followed by six years as a Board Member (the first full-time practitioner to be chosen for this post) and then a three-year term as the Chair of the Committee for Recent Advances in Endocrinology. He is now in his fifth year as a Member of the SEP Work Group for Endocrinology, Diabetes and Metabolism. His questions are always well crafted, practical, and highly rated by the (very critical) reviewers. 
As a regional leader in endocrinology, Dr Nagelberg served as Secretary-Treasurer, Vice President and President of the Philadelphia Endocrine Society, the nation's oldest local society of its kind. He has also served on important Endocrine Society Committees: the Clinical Initiatives Committee and the Clinical Endocrinology Update Steering Committee. He is now serving on the Clinical Affairs Core Committee and also serves as an abstract/poster reviewer for the Annual Meeting.

For almost three decades, Dr Nagelberg has been an outstanding contributor to the field of endocrinology as a clinician, educator, and leader both in Philadelphia and nationally. He exemplifies the best qualities of the physician-in-practice membership of The Endocrine Society: clinical acumen, service to patients, outstanding teaching, capable leadership, and generosity to his patients, students, staff, and colleagues.

On a personal note, Dr Nagelberg has been married to his wife Debra for 33 years. They have two children, Michael, a vice president with Deutsche Bank in Manhattan, New York, and Charlotte, a registered nurse in Denver, Colorado. Dr Nagelberg ran competitively until just a few years ago. His personal best time in a marathon is $2: 51-$ a blistering $6: 30$ pace for 26.2 miles! He continues to stay in excellent physical shape, training for and competing in triathlon events.

Bradley Anawalt 